http://jmscr.igmpublication.org/home/ ISSN (e)-2347-176x ISSN (p) 2455-0450

crossref DOI: https://dx.doi.org/10.18535/jmscr/v7i9.21

\title{
Evaluation of Risk factors in diabetic foot ulcers patient as predictors of lower extremity amputation: a hospital-based case control study
}

\author{
Author \\ Abdulbassit M. Alshallwi \\ Department of Surgery, Faculty of Medicine- Omar Almukhtar University \\ *Corresponding Author \\ Dr Abdulbassit M.Alshallwi \\ Associated Professor, Department of surgery \\ Faculty of Medicine- Omar Almukhtar University
}

\begin{abstract}
Background: Diabetic foot ulcers (DFU) may cause significant morbidity and lower extremity amputation (LEA) compared to the general population. The purpose of the present study was to quantify the risk factors of subsequent amputation in hospitalized Diabetic foot ulcers (DFU) patients.

Methods: We performed a hospital-based, case-control study of 94 DFU patients with LEA and 94 control DFU patients without LEA, the control subjects were matched to cases in respect to age, sex, and nutritional status, with ratio of 1:1. This study was conducted in Derna Teaching Hospital between January 2016 and December 2018, patients' demographical data and all risk factors-related information were collected from clinical records using pre-designed format, using (LEA) as the outcome variable, we calculated odds ratios (ORs) and 95\% confidence intervals (CIs) by logistic regression, which used to assess the independent effect of selected risk factors associated with LEA, the data were analyzed in SPSS version 21.

Results: There were 94 case-control pairs, all of which were diagnosed with type 2 diabetes mellitus, seven potential independent variables show a promise of influence, the latter being defined as p50.15 upon univariate analysis, multivariable logistic regression identified levels of HbAlc 8\% (OR 20.47, 95\% CI 3.12-134.31; p-0.002), presence of peripheral arterial disease (PAD) (OR 12.97, 95\% CI 3.44-48.88; pB0.001), hypertriglyceridemia (OR 5.58, 95\% CI 1.74-17.91; p-0.004), and hypertension (OR 3.67, 95\% CI 1.14-11.79; p-0.028) as the independent risk factors associated with subsequent lower extremity amputation in Diabetic foot ulcers.

Conclusions: Several risk factors for LEA were identified, we found that HbAlc >8\%, PAD, hypertriglyceridemia, and hypertension have been recognized as the predictors of LEA in this study, good glycemic control, active investigation against PAD, and management of comorbidities such as hypertriglycemia and hypertension are considered important to reduce amputation risk.

Keywords: diabetic foot ulcers; hospitalized patients; risk factors; amputation.
\end{abstract}

\section{Introduction}

Diabetes mellitus is the most common endocrine disorder known for its multifaceted complications, including diabetic foot ulcers (DFU) which often result in amputation as one of the worst outcomes $^{(1)}$, Among persons with diabetes, the 
prevalence of foot ulcers ranges from 4 to $10 \%$ and its lifetime incidence may be as high as $25 \%$ (2), foot ulceration poses a distinct barrier to conservative therapies attribute to difficulty in properly offloading the wounds, in- ability to provide daily foot hygiene, and compromised distal vascular flow in diabetes, DFU are difficult to treat, frequently get infected, and become a leading cause of diabetes-related hospital $\operatorname{admission}^{(1,3)}$, Compared to healthy persons, diabetes mellitus holds a 15- to 20-fold increased risk of lower extremity amputations (LEA) and the majority of diabetes amputation are reported to be preceded (up to 85\%) by a poor healing ulcer (4), in the future diabetes-related LEA will remain a source of significant morbidity and also mortality, considering the rapidly growing diabetes population worldwide and the high incidence of $\mathrm{DFU}^{(5)}$, according to the Global Lower Extremity Study Group LEA can be defined as a complete loss of any part of the lower extremity irrespective of the causes ${ }^{(6)}$. most of LEAs follows foot ulceration on patients with diabetes, ${ }^{(7)}$. The pathway to ulceration and finally LEA may include essential contribution from underlying diabetes-related pathophysiology (neuropathy, peripheral arterial disease (PAD), foot deformity and limited joint mobility), initiating environments (trauma), subsequent infection, and healing complications ${ }^{(8)}$. LEA is performed for various indications including severe soft-tissue infection, osteomyelitis, peripheral arterial occlusion, and gangrene, following a LEA surgery, the impact of this procedure on an individual patient is very enormous so that amputation is always considered as the last resort of any unsalvageable limb ${ }^{(9)}$, apart from its causes all attempts should be made to avoid amputation once DFU has developed or presents itself in the hospital $^{(1,4,5)}$, the question is why some patients with DFU be necessary for LEA while others were not, previous studies have revealed that duration of diabetes mellitus ${ }^{(10,11)}$, previous amputation or foot ulceration ${ }^{(10,12)}$, poor glycemic control $^{(10,12,13,14)}$, hypertension ${ }^{(15)}$, dyslipidemia
${ }^{(11,15)}$, presence of $\operatorname{PAD}^{(11,12,14)}$, peripheral neuropathy ${ }^{(13,14)}$, osteomyelitis and wound severity are independent predictors for LEA, additional factors include, older age, smoking history, anemia, leukocytosis), as well as presence of other microvascular ${ }^{(10,11,13,15,17)}$, hypoalbuminemia ${ }^{(18)}$ and macrovascular comorbidities ${ }^{(13,15)}$, however, different studies show different results and the published data that identify such risk factors for diabetes-related LEA in Libya are scanty.

\section{Material and methods}

\section{Study area and background}

This study used an observational design and was conducted in Derna Hospital, the incidence of LEA was determined by reviewing the medical records, the complete list of DFU and LEA population was identified from hospital databases (operation theatre and medical record), ulcer and gangrene due to reasons other than diabetes mellitus, and signs of acute peripheral arterial thrombosis were not included in this study, traumatic amputations and those unrelated to diabetes mellitus were also excluded, the study was designed as a matched case-control study, sample size of at least 94 in each group was needed to detect an odds ratio (OR) of 2.0 at $95 \%$ level of confidence interval (CI) with a power of 90\% (two tails), we have identified hospitalized patients who had foot ulcerations, We designed the study to have 1:1 matching, with one subject control for each case, The confounding factors such as age, sex, and nutritional status were considered in the case-control matching. The presence of the following factors was evaluated to determine if they predicted either amputation or not: demographic characteristics (duration of ulcer, duration of diabetes since diagnosed, sort of diabetes treatment), clinical features (presence and assessment of diabetic peripheral neuropathy, retinopathy, nephropathy, $\mathrm{PAD}$, and type of diabetic foot), level of glycemic control, and several laboratory data, these possible risk factors were chosen because they were common risk 
factors for LEA cited from the previous studies (10), the study period was January 2012 to December 2014 and medical records that contain missing data on any of the stratified information were excluded from analysis.

Treatment settings We utilized a standard protocol for the management of patients hospitalized because of DFU which include assessment of vascular status, assessment of neuropathy, treatment of PAD, and regular wound debridement, in general, DFU patients with signs of significant infection, such as extensive cellulitis, necrotizing fasciitis, deep abscess or osteomyelitis, septic foot, or presence of gangrenous tissue were hospitalized for intensive surgical management, all patients were placed on bed rest for pressure relief and appropriate antibiotic therapy was administered when infection was present. DFU subsequently were managed according to the severity of lesions; debridement, incision/drainage, and amputation were done as necessary.

Measurements of potential risk factors We abstracted the medical records for each hospitalization and the operative reports were read to evaluate the exact surgical procedure performed, by using a pre-formed customized chart, we collected the information regarding the patient's age, sex, body mass index (BMI), admission dates, duration of diabetes mellitus, therapeutic regimen, characterization of ulcer, ulcer duration, hemoglobin level, leukocytes count, creatinine serum, admission plasma glucose, fasting plasma glucose (FPG), HbA1c, and lipid profile (total cholesterol, fasting triglycerides, low-density lipoprotein (LDL)cholesterol, and high-density lipoprotein (HDL)cholesterol), as well as diabetes micro- and macrovascular complications (retinopathy, nephropathy, neuropathy, cerebrovascular, cardiovascular, and PAD), comorbidities such as hypertension was reported as well

Definition of wound grading and indications for LEA The DFU were graded according to Wagner classification (grade 0: high-risk foot, grade 1: superficial ulcer, grade 2: deep ulcer penetrating to tendon, bone, or joint, grade 3: deep ulcer with abscess or osteomyelitis, grade 4: localized gangrene, and grade 5: extensive gangrene $)^{(20)}$, the indication for LEA included severe soft tissue infection, osteomyelitis, or gangrene $^{(1,9)}$. This decision was made by surgeons, patient and family conference; minor amputations were included if they were within one of the following categories: partial toe amputation, complete toe disarticulation at the metatarsophalangeal joint, ray (toe and metatarsal) amputation, or proximal foot amputation (transmetatarsal, Lisfranc's, Chopart's, and Syme's), whiletrans-tibial and trans-femoral amputation were considered as major amputations ${ }^{(9)}$.

\section{Case-control classification}

Cases subjects included DFU patients admitted to Derna Hospital with at least one subsequent lower extremity amputation during the study period, from total amputation surgeries were initially identified some patients were subsequently excluded for the following reasons: DFUs included in Wagner grade 5 lesion, unable to retrieve a complete medical record, unable to find a control suitable for matching, this left 94 patients with LEA in confirmed diabetic patients available for the study, of these, 74 patients (78.7\%) had minor amputation and the remainder 20 patients $(21.3 \%)$ had major amputation. Control subjects were patients with DFU who had never undergone LEA during the time of hospitalization,, an attempt was made to individually match one control per case by pairing patients with sex and age, nutritional status based on their BMI ,in this process some potential control subjects were excluded because the necessary data was incomplete or there was no corresponding match with the case subjects, the final 94 control subjects were verified after all studied patients had been evaluated and one control subject for each case with LEA.

Statistical analysis Descriptive statistics were obtained to describe the characteristics of the studied population, the variables of interest were 
selected and these potential risk factors were compared on matched pairs of case and control subjects, ORs greater than 1 indicate an increased LEA risk for the corresponding variable using a conditional logistic regression, accordingly, we created a dummy variable for each of the selected risk factors and examined their effects (adjusted to age, sex, and nutritional status) on LEA risk, second all potential predictors (variables selected through univariate analysis) were entered simultaneously in a multivariable logistic regression model that was reduced using a backward selection method, in the multivariable logistic regression the analysis was performed in a full model the Hosmer Lemeshow $\mathrm{X}^{2}$ goodnessof-fit test was used for model building ,comparison between patients who did and did not develop an LEA was assessed using the Area under the Receiver Operating Characteristic Curve (ROC) with 95\% CI, the Statistical Package for Social Science (IBM version 21.0; SPSS Inc., Chicago, USA) was used for all data analysis.

Table 1 Univariate analysis of risk factors associated with lower extremity amputation

\begin{tabular}{|c|c|c|c|c|c|}
\hline & Non-amputation $\mathrm{n}(\%)$ & Amputation $\mathrm{n}(\%)$ & OR & $95 \% \mathrm{CI}$ & $\mathrm{p}$ \\
\hline Age $\geq 60$ years & $12(6.4 \%)$ & $24(12.7 \%)$ & 2.34 & $0.79-6.89$ & 0.122 \\
\hline Duration of diabetes $>5$ years & $40(21.3 \%)$ & $52(27.6 \%)$ & 1.67 & $0.73-3.77$ & 0.217 \\
\hline $\mathrm{FPG} \geq 126 \mathrm{mg} / \mathrm{dL}(\mathrm{mg} / \mathrm{dL})$ & $78(41.4 \%)$ & $92(48.9 \%)$ & 9.43 & $1.13-78.78$ & $0.038^{*}$ \\
\hline $\mathrm{HbA} 1 \mathrm{c} \geq 8 \%$ & $66(35.1 \%)$ & $90(47.8 \%)$ & 9.54 & $2.03-44.89$ & $0.004 *$ \\
\hline Leukocyte count $\geq 15 \times 103 / \mu \mathrm{L}$ & $52(27.6 \%)$ & $54(28.7 \%)$ & 1.09 & $0.42-2.46$ & 0.835 \\
\hline S. creatinine $\geq 1.5 \mathrm{~g} / \mathrm{dL}$ & $30(15.9 \%)$ & $26(13.8 \%)$ & 1.22 & $0.50-2.97$ & 0.692 \\
\hline cholesterol $\geq 200 \mathrm{mg} / \mathrm{dL}$ & $12(6.4 \%)$ & $18(9.5 \%)$ & 1.07 & $0.69-1.67$ & 0.736 \\
\hline Triglycerides $\geq 150 \mathrm{mg} / \mathrm{dL}$ & $34(18.1 \%)$ & $66(35.1 \%)$ & 2.14 & $1.13-4.04$ & $0.019 *$ \\
\hline Hypertension status & $38(20.2 \%)$ & $62(32.9 \%)$ & 2.85 & $1.23-6.60$ & $0.014 *$ \\
\hline Presence of CAD & $26(13.8 \%)$ & $16(8.5 \%)$ & 1.14 & $0.72-1.81$ & 0.559 \\
\hline Diabetic retinopathy & $84(44.7 \%)$ & $90(47.8 \%)$ & 2.50 & $0.48-12.88$ & 0.273 \\
\hline Diabetic nephropathy & $50(26.6 \%)$ & $52(27.6 \%)$ & 1.04 & $0.57-1.90$ & 0.879 \\
\hline Diabetic neuropathy & $60(31.9 \%)$ & $68(36.2 \%)$ & 1.30 & $0.63-2.69$ & 0.467 \\
\hline Diabetes with PAD & $18(9.6 \%)$ & $58(30.8 \%)$ & 2.11 & $1.20-3.69$ & $0.009 *$ \\
\hline Wagner Grade $1+2$ & $42(22.3 \%)$ & $4(2.1 \%)$ & 1.00 & & \\
\hline Wagner Grade 3 & $46(24.4 \%)$ & $30(15.9 \%)$ & 1.53 & $0.80-2.93$ & 0.198 \\
\hline Wagner Grade 4 & $6(3.2 \%)$ & $60(31.9 \%)$ & 10.00 & $3.05-32.76$ & $<0.001^{*}$ \\
\hline
\end{tabular}

Table 2 displays the adjusted multivariable logistic regression and, among others, the status, triglyceride] $150 \mathrm{mg} / \mathrm{dL}$, diabetes with PAD and $\mathrm{HbA} 1 \mathrm{c}>8 \%$

\section{Results and Discussion}

Univariate analysis of LEA risk factors Table 1 shows a comparison between the cases and control group to indicate the corresponding ORs for outcome and significant risk factors namely: hypertension status, presence of PAD, foot necrosis or gangrene, $\mathrm{HbA} 1 \mathrm{c}$ and triglycerides, other variables included in the logistic regression model were found not significant in determining the risk of amputation, univariate analysis of the amputation risk versus exploratory variables showed that, out of 27 variables, only seven showed a promise of influence, the latter being defined as p50.15 finally, in a stepwise manner, logistic regression analysis was performed of the amputation risk vs the remaining seven variables simultaneously starting with afull model and removing non-significant variables one by one, the final result was a model with adjusted significant predictors of an LEA.

independent risk factors of LEA are hypertension

Table 2 Final logistic model for multivariate (adjusted) risk factors of lower extremity amputation

\begin{tabular}{|l|c|c|c|c|}
\hline & \multicolumn{4}{|c|}{ Amputation (n=94) } \\
\hline & $\beta$-coefficient & Adjusted OR & $95 \%$ CI & $\mathrm{p}$ \\
\hline Hypertension status & 1.30 & 3.67 & $1.14-11.79$ & $0.028^{*}$ \\
\hline Triglycerides $\geq 150 \mathrm{mg} / \mathrm{dL}$ & 1.72 & 5.58 & $1.74-17.91$ & $0.004^{*}$ \\
\hline FPG $\geq 126 \mathrm{mg} / \mathrm{dL}$ & 2.16 & 8.67 & $0.74-101.11$ & 0.085 \\
\hline Diabetes with PAD & 2.56 & 12.97 & $3.44-48.88$ & $<0.001^{*}$ \\
\hline HbA1c $\geq 8 \%$ & 3.01 & 20.47 & $3.12-134.31$ & $0.002^{*}$ \\
\hline
\end{tabular}


To describe the severity of DFU, we used the diabetic foot classification systems: Wagner grade (32), in a Turkish cohort, Yesil et al. reported that Wagner grade (Wagner grade 4 and 5) was a strong predictor for LEA ${ }^{(22)}$, our study revealed that $95.7 \%$ of the cases were classified as high grade lesion>grade 3) we obtained a 10-fold increased risk of amputation when DFU severity at admission was at least Wagner grade 4 when compared to grade 1 and grade 2, also we found that DFU that penetrated to bone was not merely a risk factor but the presence of gangrene became a very strong reason for an LEA (OR 25.88, 95\%CI 6.9796.13; pB0.001), in our hospital the patients avoid admission except in more advanced DFU with an increased risk of extensive surgical management, This fact becomes a relatively common scenario in developing countries and brings considerable delay for optimal management when an amputation surgery was inevitable ${ }^{(35)}$, In our study, the prevalence of PAD is higher in the case subjects, as many as $61.7 \%$ compared to $9.6 \%$ on the control group (p0.009), the patients with most likelihood to present with LEA were those with neuroischemic ulcer (OR 3.22, 95\% CI $1.526 .80 ; \mathrm{p} 0.002)$ compared to only neuropathic ulcer. The most important finding in our study was that poorglycemic control had a major role in the development of LEA, Table 2 show that the diabetics in our studied population was poorly controlled, HbA1c above $8 \%$ was a significant risk factor for LEA (OR 20.47, 95\%CI 3.44134.31; p0.002), those reported by Moss et al. ${ }^{(10)}$, Miyajima et al. from Japan $^{(17)}$ The strong association of HbAlc with LEA could reflect a greater pathogenic role of chronic hyperglycemia probably via neuropathy, autonomic dysfunction, PAD, and susceptibility to infection ${ }^{(22,23)}$. The United Kingdom Prospective Diabetes Study ${ }^{(24)}$ reported that the hazard ratio of death from amputation declines $43 \%$ when HbAlc declines by $1 \%$.The Steno-2 study ${ }^{(25)}$ has shown that an intensified multifactorial intervention including tight glucose control reduces the risk of vascular complication by half, and significantly lowers the amputation rate compared to standard treatment for patients with type 2 diabetes, however, from Table 3 of our study, we can conclude that as many as $27.6 \%$ of cases compared to $21.3 \%$ of control had diabetes for more than5 years ( $p$ 0.217) and the clinical duration of diabetes was not related to the risk of amputation, our finding was similar to many other studies that claimed the duration of diabetes is not a baseline factor that predicts amputation $^{(17,19,22)}$. Reiber et al. ${ }^{(20)}$ also reported the non-differences in the risk of LEA by the duration of diabetes but the risk can be explained better by the level of glycaemia control Hypertension also contributes to the development and progression of chronic diabetes complications and it is considered as an established risk factor for atherosclerosis ${ }^{(30)}$, the data concerning the importance of blood pressure as a predictor of LEA are somehow conflicting, in American Indians, systolic blood pressure was found to be an important predictor of LEA $^{(16)}$ In our studythere were significantly more recorded diagnoses of hypertension in case subjects compared to control group (32.9\% vs. $20.2 \%$,p0.013 Our finding was in accordance with Wisconsin Epidemiologic Study which shows that blood pressure and $\mathrm{HbA} 1 \mathrm{c}$ were related to amputation risk but that nephropathy and retinopathy were at most only weakly correlated $^{(10)}$.

In our study, infectious events occurred in nearly all lesions (98.8\%), compared to other studies, the prevalence of infection in our study was higher which may be related to uncontrolled hyperglycemia, presence of PAD, and cultural differences in foot care. More severe infection (PEDIS grade 3 and 4) is associated with higher rates of LEA than milder one (45.7 vs $39.3 \%$ p0.138) , the success in eradicating osteomyelitis in 27 out of 52 patients $(53 \%)$ by conservative approach and suggested a good outcome without the need for surgical procedure in the absence 
of extensive necrosis or gangrene. Many factors influence the decision of whether or not an LEA should be performed on a patient with DFU Lipsky et al. ${ }^{(54)}$ reported that LEAs were higher for patients with surgical site infection, vasculopathy, amputation history, and high leukocyte count, we added a few more variables to this suggested model and identified a typology of risk for LEA in DFU patients with an average HbA1c>8\%, along with the presence of PAD, hyper triglyceridemia, and hypertension, accordingly, diabetic patients with foot ulcers with the above-mentioned profile should be considered to be at high risk of LEA and signal the need for close monitoring by health care professions

\section{Conclusions}

In the results of our analysis, poor glycemic control, the presence of PAD, hyper triglyceridemia, and hypertension status were independent risk factors for LEA, this study indirectly implies that early intervention before critical DFU has developed might help to prevent diabetes-related LEA. Strict control of diabetes, which is the primary disease, is first of all required for the risk reduction, for the PAD, active investigation of each patient is necessary to assess the possibility of revascularization and the probability of wound healing, this study indicates that triglyceride and hypertension control both may be an important additional primary prevention effort, we suggest that prospective studies and multicenter designs involving more detailed risk factors should be undertaken in the future for further conclusions.

\section{References}

1. Djokomoeljanto R. Tinjauan umum tentang kaki diabetes.In: Djokomoeljanto R, Darmono, Suhartono T, eds. Kakidiabetik: Patogenesis dan penatalaksanaan. Semarang: Dipo-negoro University; 1997, pp. 110.
2. Reiber GE. The epidemiology of diabetic foot problems. Diabetic Med 1996; $13: 611$.

3. Thewjitcharoen Y, Krittiyawong S, Porramatikul S, Parksook W, Chatapat L, Watchareejirachot $\mathrm{O}$, et al. Outcomes ofhospitalized diabetic foot patients in a multi-disciplinary teamsetting: Thailand's experience. J Clin Transl Endocrinol 2014; 1:18791.

4. van Houtum WH. Diabetes related lower extremity ampu-tations. Master dissertation, Vrije University, Amsterdam The Netherland, 1998.

5. Abbas ZG. Reducing diabetic limb amputations in developingcountries. Expert Rev Endocrinol Metab 2015; 10: 42534.

6. Unwin N, Mackintosh J, La Porte R, Chang YF, Renzie R, onbehalf of The Global Lower Extremity Study Group. Epide-miology of lower extremity amputation in centres in Europe, North America and East Asia. Br J Surg 2000; 87: 32837.

7. Dillingham TR, Pezzin LE, MacKenzie EJ. Limb amputationand limb deficiency: epidemiology and recent trends in the United States. South Med J 2002; 95: 87583.

8. Pecoraro RE, Reiber GE, Burgess EM. Pathways to diabeticlimb amputation: basis for prevention. Diabetes Care 1990; 13:51321.

9. Bowker JH. Minor and major lower limb amputations anddisarticulations in patients with diabetes mellitus. In: BowkerJH, Pfeifer MA, eds. Levin and O'Neal's: the diabetic foot.Philadelphia, PA: Mosby Elsevier; 2008, pp. 40328.

10. Moss SE, Klein R, Klein BEK. The prevalence and incidence of lower extremity amputation in a diabetic population. Arch Intern Med 1992; 152: 61016. 
11. Lehto S, Ronnemaa T, Pyorala K, Laakso M. Risk factors pre-dicting lower extremity amputation in patients with NIDDM. Diabetes Care 1996; 19: 60712.

12. Shojaiefard A, Khorgami Z, Larijani B. Independent risk factors for amputation in diabetic foot. Int $\mathbf{J}$ Diabetes Dev Ctries 2008; 28: 327.

13. Lacle A, Valero-Juan LF. Diabetesrelated lower-extremity amputation incidence and risk factors: a prospective seven-yearstudy in Costa Rica. Rev Panam Salud Publica 2012; 32: 1928.

14. Martins-Mendes D, Monteiro-Soares M, Boyko EJ, Ribeiro M,Barata P, Lima J, et al. The independent contribution of diabeticfoot ulcer on lower extremity amputation and mortality risk.J Diabetes Complications 2014; 28: 6328.

15. Lee JS, Lu ML, Lee VS, Russel D, Bahr C, Lee ET. Lower-extremity amputation: incidence, risk factors and mortalityin the Oklahoma Indian Diabetes Study. Diabetes 1993; 42:87682.

16. Resnick HE, Carter EA, Sosenko JM, Henly SJ, Fabsitz RR,Ness FK, et al. Incidence of lower-extremity amputation inAmerican Indians: the Strong Heart Study. Diabetes Care 2004;27: 188591.

17. Miyajima S, Shirai A, Yamamoto S, Okada N, Matsushita T.Risk factors for major limb amputations in diabetic footgangrene patients. Diabetes Res Clin Pract 2006; 71: 2729.

18. Aziz Z, Lin WK, Nather A, Huak CY. Predictive factors forlower extremity amputations in diabetic foot infections. DiabeticFoot Ankle 2011; 2. doi: http://dx.doi.org/10.3402/dfa.v2i0.7463
19. Zubair M, Malik A, Ahmad J. Incidence, risk factors foramputation among patients with diabetic foot ulcer in a NorthIndian tertiary care hospital. Foot 2012; 22: 2430.

20. Wagner FW Jr. The diabetic foot. Orthopedics 1987; 10: 16372..

21. Hosmer DW, Lemeshow S. Applied logistic regression, 2nd ed.Hoboken, $\mathrm{NJ}$ : Wiley; 2000.

22. Marcovecchio ML, Lucantoni M, Chiarelli F. Role of chronicand acute hyperglycemia in the development of diabetes complications. Diabetes Technol Ther 2011; 13: 38994.

23. Adler AI, Erqou S, Lima TA, Robinson AH. Association between glycated hemoglobin and the risk of lower extremity amputation in patients with diabetes mellitus review andmetaanalysis. Diabetologia 2010; 53: 8409.

24. Stratton IM, Adler AI, Neil HA, Matthews DR, Manley SE, Cull CA, et al. Association of glycemia with macro vascular and microvascular complications of type 2 diabetes (UKPDS 35): prospective observational study. BMJ 2000; 321: 40512.

25. Gaede P, Lund-Andersen H, Parving HH, Pedersen O. Effect ofa multifactorial intervention on mortality in type 2 diabetes. NEngl J Med 2008; 358: 58091.

26. Lipsky BA, Weigelt JA, Sun X, Johannes RS, Derby KG, TabakYP. Developing and validating a risk score for lower-extremity amputation in patients hospitalized for a diabetic foot infection. Diabetes Care 2011; 34: 169570. 